\title{
Adaptation Of Nusantara Fable Story In A Circus Show
}

\section{Adaptasi Cerita Fabel Nusantara Dalam Pertunjukan Sirkus}

\author{
Greta Ariati Mulyosantoso ${ }^{1}$, Chrisdina $\mathrm{Wempi}^{2}$ \\ ${ }^{1}$ Faculty of Communication, LSPR Communication and Business Institute, Indonesia \\ ${ }^{2}$ Sudirman Park, LSPR Communication and Business Institute, INDONESIA \\ Authors'email: '1greta.am@1spr.edu; ${ }^{2}$ chrisdina@1spr.edu
}

Published: 28 September 2020

\begin{abstract}
Along with the times, traditional arts slowly began to fade. So, it is with traditional folk tales. It is important to keep traditional stories known and understood by children. Introducing the arts, especially performing arts, can be done from an early age, carried out by parents, teachers, to certain communities. For children, of course, an easy and interesting way is needed so that they can be enjoyed until a show is over. The concept of the show 'The Fabulous Fable Show; Circus and Theater 'is a concept that was initiated as a form of love for the local culture of the archipelago, collaborated with circus performances as one of the main branches of the performing arts. Circus shows generally feature attractions such as juggling, spinning, acrobatics, or attractions that use animals such as lions, tigers, elephants, and others. To make this show even more interesting, the concept maker included a theatrical element by bringing up the fable story from Indonesia. The fable story was chosen because the characters used were taken from animals and made children interested in the play that was performed. From there, children can recognize emotional expressions, such as joy or sadness that arise from a dance movement or song that is played.
\end{abstract}

Keywords: Circus, Fable, Indonesia, Performing Arts

eISSN: 2550-214X (C) 2020. The Authors. Published for Idealogy Journal by UiTM Press. This is an Open Access article distributed under the terms of the Creative Commons Attribution-NonCommercial-NoDerivatives License (http://creativecommons.org/licenses/by-nc-nd/4.0/), which permits non-commercial re-use, distribution, and reproduction in any medium, provided the original work is properly cited, and is not altered, transformed, or built upon in any way.

\section{LATAR BELAKANG}

Seni merupakan bagian dari kehidupan manusia dan masyarakat. Dalam masyarakat Indonesia baru atau modern, seni pertunjukan adalah kegiatan di luar kegiatan kerja sehari-hari. Dalam masyarakat Indonesia sekarang, yang dimaksud dengan seni, \& Jaeni, 2001, p.1-3).

Menurut Sedyawati $(2012 ; 289)$ seni pertunjukan pertunjukan dapat terdiri dari seni tari, seni teater, seni musik, seni pantomim, seni baca puisi dan lain-lain (Sumardjo, Dwimarwati merupakan sesuatu yang dipertunjukan kepada khalayak banyak untuk memberikan hiburan yang dapat dinikmati oleh para penontonnya. Seni pertunjukan dibagi menjadi dua bentuk format penyajiannya, bentuk yang pertama, seni pertunjukan dengan pendekatan tradisional dan bentuk kedua adalah seni pertunjukan dengan pendekatan modern atau seni pertunjukan yang muncul dan berkembang belakang ini yang biasa diistilahkan dengan seni pertunjukan kontemporer.

Memperkenalkan kesenian, khususnya seni pertunjukan dapat dilakukan semenjak usia dini. Peran memperkenalkan hal tersebut dapat dilakukan oleh orang tua, pengajar, hingga komunitas tertentu. Pada anak-anak tentunya diperlukan cara yang mudah serta menarik sehingga dapat dinikmati hingga sebuah pertunjukan selesai.

Fungsi dari seni pertunjukan bukan hanya pada penajaman rasa berkesenian saja tetapi dapat juga menjadi medium dalam menyampaikan pesan nilai moral. Pemahaman akan moral yang bersifat abstrak 
akan menjadi lebih mudah untuk dipahami apabila diberikan dalam bentuk cerita dalam nuansa anakanak serta format yang modern (kekinian). Dengan kemajuan bentuk animasi, teknologi, serta beragam sumber informasi maka pendekatan kepada anak menjadi lebih beragam.

Pemahaman akan modernisasi tentunya jangan ditekankan pada alur cerita saja, tetapi pada pengemasan dari seni pertunjukan. Hal ini menjadi penting untuk tetap menjaga cerita tradisional yang dikenal dan dipahami oleh anak-anak. Cerita tradisional yang terkadang terkesan kuno dan tidak menarik menjadi sebuah tantangan tersendiri bagi penggerak seni untuk dapat menyiasati kondisi tersebut.

Kehidupan dan perkembangan kesenian baik secara luas dan seni pertunjukan secara khusus sangat dipengaruhi oleh faktor lingkungan, pendidikan, politik serta teknologi. Faktor-faktor tersebut akan menuntun selera dan kecenderungan setiap bagian masyarakat dalam berkarya dan juga dalam menikmati karya seni budaya yang ada dan hidup.

Dengan kemajuan zaman, perkembangan seni pertunjukan dapat dilakukan melalui panggung indoor seperti teater, seni tari, dan seni musik. Sedangkan panggung outdoor, antara lain opera dan sirkus cukup jarang ditampilkan di Indonesia walaupun keduanya merupakan pertunjukan yang sangat menarik. Hal tersebut kemungkinan terjadi disebabkan budaya barat yang cukup kental melatar belakangi keduanya.

Sehubungan dengan memperkenalkan seni kepada anak-anak, salah satu yang cukup menarik adalah pertunjukan sirkus. Di Indonesia Sirkus dapat disaksikan di beberapa tempat dan waktu tertentu, seperti yang diadakan di pusat perbelanjaan atau di tempat rekreasi kebun binatang. Penonton yang mayoritas orang tua dengan membawa anak menjadi hal yang menarik untuk menjadi perhatian. Mulai dari anakanak, remaja hingga orang dewasa, tak ada yang mengaku tak terhibur sehabis menonton aksi akrobat yang membuat hati berdebar dan tingkah konyol badut yang membuat penonton terpingkal (CNN Indonesia, 2018).

Rizqi (2018) mengatakan salah satu cara untuk mendukung perkembangan anak-anak adalah dengan mengajaknya menonton pertunjukan, baik itu opera, sirkus, pentas binatang atau tarian. Hal tersebut akan bisa membantu anak belajar banyak hal. Anak-anak dapat mengenal ekspresi emosi, seperti gembira atau sedih yang muncul dari gerakan tari atau lagu yang diputar. Selain itu, mereka juga bisa belajar beradaptasi dengan lokasi pertunjukan yang cenderung besar, dengan banyaknya properti dan kebisingan penonton lainnya. Mengamati kondisi tersebut nampak bahwa ada celah tertentu yang dapat dilakukan dengan menggunakan media sirkus.

Istilah sirkus, yang berasal dari kata latin, circus atau circulus yaitu lingkaran, yang mengacu pada pertunjukan hiburan, termasuk akrobat di arena yang berbentuk lingkaran (Pengertian Sirkus, 2014, n.d.). Para pemain sirkus menampilkan pertunjukan yang interaktif dengan kemampuan kelenturan tubuh dan luar biasa yang tidak semua orang bisa melakukannya. Beberapa pertunjukan sirkus juga seringkali melibatkan hewan-hewan terlatih dengan seorang pawang yang profesional.

Pertunjukan sirkus yang biasa ditampilkan di Indonesia memiliki alur pementasan yang terbagi-bagi secara segmen. Setiap pembagian memiliki tema tertentu seperti menyadur budaya dari negara dari mana atraksi berasal atau asal dari hewan tertentu. Penyampaian pertunjukan tersebut masih dapat dikembangkan khususnya dalam memaksimalkan faktor teatrikal yang menggabungkan dengan konsep penggunaan tokoh binatang yang mewakili sebuah karakter atau biasa disebut Fabel.

Fabel adalah cerita yang dibuat dengan menggunakan hewan sebagai tokohnya yang menggambarkan karakter manusia (Zaidan, 2007; Nurgiyantoro, 2010). Cerita Fabel dalam proses pembentukannya mengandung nilai-nilai dan ajaran moral yang dimana manfaatnya dapat dirasakan langsung oleh pembaca terutama anak-anak (Ampera, 2010). 
Pengamatan pada fenomena pengenalan seni tradisional menggunakan media sirkus menjadi sangat menarik untuk dikembangkan. Melalui studi ini ingin dicari bagaimana cerita rakyat yang dikemas dalam fabel serta dipertunjukan dalam sirkus dapat membangun kesadaran serta ketertarikan anak-anak pada budaya lokal. Selain itu melalui studi ini dapat membentuk ketertarikan pada penelitian yang fokus pada seni pertunjukan kolaboratif dari berbagai budaya yang digabungkan.

\section{METODE DAN PEMBAHASAN}

Hidayat (2018) dalam portal berita Antara - Jambi mendeskripsikan sirkus adalah sekelompok orang yang berkelana untuk menghibur penonton dengan atraksi akrobat, badut, binatang terlatih, aksi trapeze, berjalan di atas tali, juggling, sepeda roda satu, dan hiburan-hiburan lainnya. Biasanya dipadukan dengan musik atau efek suara lainnya.

Sirkus dianggap sebagai hiburan terpopuler di dunia pada abad ke-19. Sirkus lahir pada tahun 1768 , oleh seorang penunggang kuda dari Inggris. Di Perancis, sirkus juga dipimpin oleh seorang penunggang kuda bernama Alexis Gruss, Jr. Selanjutnya, setelah melihat peningkatan sebanyak 12 persen setiap tahunnya, Amerika ikut mendirikan sirkus yang diawali oleh munculnya Ringling Bros. dan Barnum \& Bailey Circus. Setelah itu, sirkus-sirkus tipe baru mulai bermunculan.

Tahun 80-an, sirkus mulai berubah dari sekedar karnaval menjadi sebuah budaya dan teori kritis tentang sirkus pun bermunculan. Selama tahun-tahun awal, belum ada kelas khusus yang membahas teori sirkus atau Analyse du Spectacle dikarenakan teori tersebut memang belum dibuat. Pada masanya, buku-buku tentang sirkus seperti yang bisa ditemukan di perpustakaan Baraboo, Wisconsin, merupakan buku yang berupa narasi, memoir, sejarah dan fiksi, bukan berupa pemaparan analitis (Wall, 2013).

Di dalam karya tulis elektronik Kompas mengenai kejayaan sirkus di Indonesia, diperlukan adanya manajemen pertunjukan untuk mengatur keberlangsungan pementasan dari awal sampai akhir acara. Manajemen pertunjukan tidak hanya dibutuhkan dalam satu proyek saja, melainkan disetiap proyek pementasan untuk mengemas pertunjukan menjadi lebih menarik. Mengutip artikel dari laman circusnow.org, Panolih (2020) mengatakan sirkus merupakan sebuah kesenian yang digunakan untuk menunjukkan keindahan dan ekspresi diri melalui teater, tarian dan atraksi yang dilakukan.

Manajemen seni pertunjukan merupakan hal yang penting untuk diperhatikan karena menunjang efektivitas dari pelaksanaan pertunjukan. Efektif memiliki artian dapat menghasilkan karya seni yang berkualitas sesuai dengan keinginan senimannya dan penontonnya. Selain hal tersebut juga dalam menggunakan sumber daya secara rasional dan hemat, tidak ada pemborosan atau penyimpangan.

The Event Safety Alliance dalam buku yang berjudul "The Event Safety Guide” mengatakan bahwa 'the process for planning an event can be considered in separate parts'. Beberapa orang merasa lebih mudah untuk melihat proses perencanaan sebagai perkembangan acara dengan melaksanakan tahapantahapan yang ada. Seiring berjalannya waktu, penyelenggara acara mengembangkan proses multiphase agar pembagian tugas setiap bagiannya lebih jelas. Dalam hal ini, disebutkan ada empat fase yaitu, Planning, Pre-Production, Production, dan Post Production.

Melalui studi ini akan menggabungkan dua teori manajemen pertunjukan dan konsep manajemen event. Proses tersebut harus dijalani dengan baik oleh orang-orang yang terlibat di dalamnya berdasarkan pekerjaan masing-masing mulai dari perencanaan, pengorganisasian, pengarahan dan pengendalian.

\subsection{Planning (Perencanaan)}

Planning merupakan tahapan pertama dalam membuat sebuah event. Pada tahap ini terjalin keterkaitan antara pihak-pihak penyelenggara acara, pembuatan dan persetujuan anggaran, pencarian dana dan termasuk pemilihan tempat acara dan perizinan. mengumpulkan ide dan membuat 
perencanaan-perencanaan awal seperti perencanaan biaya produksi, merencanakan pengorganisasian, menentukan target audiens, membuat timeline produksi, menyusun perencanaan promosi.

Penentuan target pengunjung diperuntukkan sebagai tolak ukur keberhasilan acara yang diselenggarakan. Bertepatan dengan visi dan misi yang telah disebutkan dalam poin sebelumnya, maka pembuat karya mengklasifikasikan target pengunjung event sebagai berikut:
i. Usia
: 6 - 35 tahun
ii. Jenis kelamin : Pria dan Wanita
iii. Kelas sosial : A dan B
iv.Pekerjaan : Pelajar, Pengusaha, Wiraswasta, Pemerhati Seni, Penikmat Seni
vi.Geografis : Jabodetabek

\subsection{Pre-Production (Pra-Produksi)}

Fase Pre-Production merupakan masa di mana penyelenggara acara mempersiapkan segala sesuatunya sebelum acara diselenggarakan. Dalam tahap Pre-Production, penyelenggara acara mengembangkan desain akhir, memilih vendor, perencanaan kesehatan dan keselamatan, perencanaan logistik, pertolongan pertama pada kecelakaan, penanggulangan kebakaran dan lain sebagainya. Pembuatan tabel production plan yang berisi penjabaran kebutuhan setiap adegan seperti properti panggung, warna lampu, suara, blocking dan lain-lain yang nantinya akan digunakan sebagai acuan produksi.

\subsubsection{Langkah Penulisan Naskah}

Untuk menghadirkan unsur teatrikal, pembuat karya mengangkat dua cerita rakyat dari Indonesia yang diadaptasi menjadi sebuah alur pertunjukan sirkus. Adapun cerita yang akan dipertunjukan adalah cerita fable berjudul 'Burung Kasuari dan Dara Mahkota' yang berasal dari Papua.

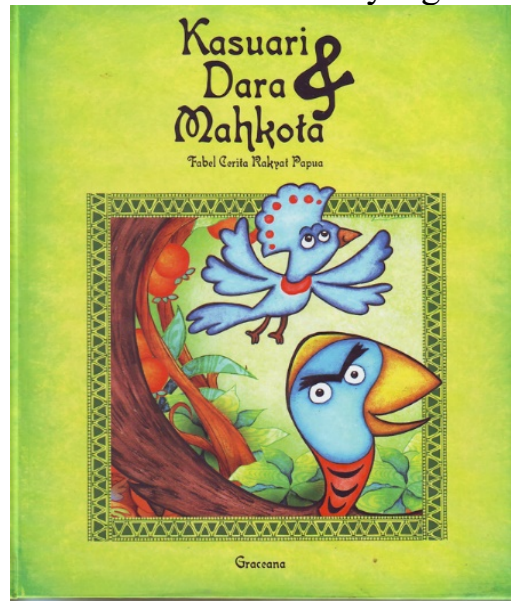

\section{Gambar 1: Kasuari \& Dara Mahkota}

(Source: http://graceana-home-made.blogspot.com/2011/05/traditional-fables-1.html)

Cerita yang dipilih memiliki nilai-nilai yang dapat diterapkan dalam kehidupan sehari-hari sehingga dapat dipergunakan sebagai pembelajaran bagi khalayak yang menonton. Pembuat karya menyusun alur tersebut ke dalam sebuah naskah pertunjukan yang dibuat melalui beberapa tahapan.

\subsubsection{Membaca Karya Asli}

Pembuat karya terlebih dahulu membaca dan memahami karya asli yang telah ditulis sebelumnya. Membaca karya asli menjadi penting untuk dapat memahami maksud dan tujuan dari cerita yang dipilih sehingga ketika menyadur menjadi bentuk dan tidak akan menghilangkan makna utama dan ciri khas tertentu. 


\subsubsection{Menulis Sinopsis Adaptasi Karya Asli}

Menulis inti cerita sesuai dengan pemahaman dan pengembangan yang dikehendaki sehingga menghasilkan sebuah karya baru yang merupakan hasil adaptasi dari karya sebelumnya.

\subsubsection{Menulis Naskah dengan Pengembangan Hasil Adaptasi}

Mengembangkan sinopsis hasil adaptasi menjadi sebuah naskah skenario dan menentukan jumlah babak. Pada studi ini penyesuaian struktur penulisan naskah panggung dibantu dengan software penulisan naskah Celtx.

\subsubsection{Studi tentang watak yang akan dibawakan oleh peranan}

Pada perencanaan kostum ini pembuat karya membaca naskah untuk mengetahui jumlah pemain, karakter, dan alur cerita pada naskah yang dibuat.

\subsection{Production (Produksi)}

Fase Produksi merupakan tahap di mana acara yang diselenggarakan berlangsung. Tahap ini dimulai ketika acara pertama sudah berlangsung di tempat acara dan berkelanjutan sampai pada akhirnya seluruh elemen acara berjalan keluar panggung.

Pada studi ini dirancang konsep pembelajaran akan cerita tradisional melalui acara 'The Fabulous Show: Circus and Theater'. Merupakan sebuah pagelaran sirkus yang dikemas dalam sebuah plot atau alur cerita. Konsep ini berbeda dari pagelaran sirkus pada umumnya. Keunikan yang ditawarkan adalah mengangkat adaptasi dari cerita fabel dari Papua berjudul 'Kasuari dan Dara Mahkota', yang dilengkapi dengan suguhan ciri khas tradisional Indonesia pada riasan dan pakaian yang dikenakan oleh para pelakunya. Seluruh pemain akan bernyanyi, menari, dan berakrobat.

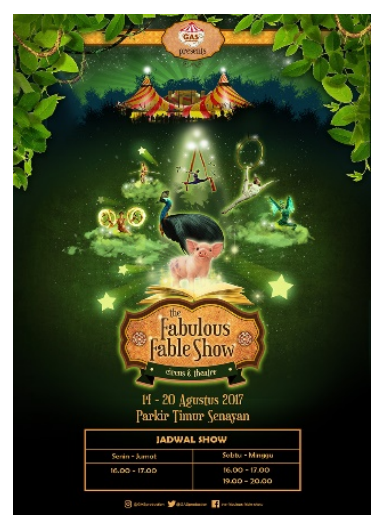

Gambar 2: Materi Publikasi 'The Fabulous Fable Show' (Sumber: Olahan Penulis, 2016)

Pertimbangan pemilihan fable adalah mengacu pada ketertarikan anak-anak pada binatang. Cerita binatang dipilih karena dekat dengan kehidupan anak-anak. Binatang yang dipilih nantinya akan mencerminkan karakteristik tertentu yang disesuaikan dengan ide cerita. Cerita binatang secara umum tidak panjang, didalamnya terdapat pesan moral dan budi pekerti yang secara nyata disampaikan di akhir cerita (Sutherland, 1991: 108). Jadi, dengan cerita binatang diharapkan anak-anak akan memperoleh cerita yang mengasyikkan dan menghibur. 
Cerita binatang yang memiliki pesan moral dan nilai-nilai budi pekerti, diharapkan dapat mempengaruhi pendidikan karakter kepada anak-anak yang datang menonton pertunjukan sirkus. Megawangi (2003) mengatakan bahwa, terdapat 4 unsur yang harus dilakukan dalam model pendidikan karakter:

1. Knowing the Good (mengetahui hal baik)

2. Reasoning the Good (alasan melakukan hal baik)

3. Feeling the Good (merasakan hal baik)

4. Acting the Good (melakukan hal baik).

Penyampaian karakter melalui tokoh binatang juga memiliki manfaat sosial, dimana seorang anak dapat belajar dari cara tokoh-tokoh tersebut berinteraksi satu sama lain untuk saling tolong menolong, bekerja sama, melakukan aktivitas bersama, toleransi, dan bermain bersama. Dari sana mereka juga dapat mengembangkan aspek bahasa yang mereka miliki, dan berguna saat mereka berinteraksi dengan orang-orang disekitarnya.

'The Fabulous Fable Show; Circus and Theatre' binatang yang dipilih adalah:

\subsubsection{Burung Kasuari}

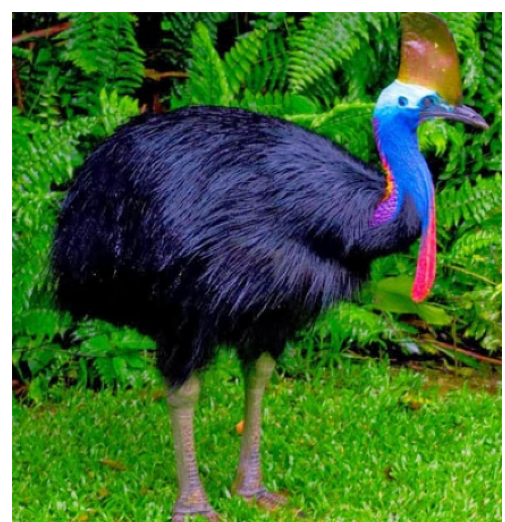

Gambar 3: Burung Kasuari

(Sumber: dongengceritarakyat.com)

Mewakili karakter Kasuari dalam cerita 'Kasuari dan Dara Mahkota'. Pemilihan kasuari didasari dengan perawakan burung kasuari yang besar dan tinggi, dilengkapi oleh bulu-bulu hitam tebal yang menutupi tubuh mereka. Di atas kepala ada semacam 'mahkota' berwarna coklat muda. Dimana melambangkan sifat asli yang dipahami oleh anak-anak yaitu gagah, sombong, menakutkan, suka bertengkar dan mencari keributan, serta suka merendahkan orang lain.

\subsubsection{Burung Dara Mahkota (Mambruk)}

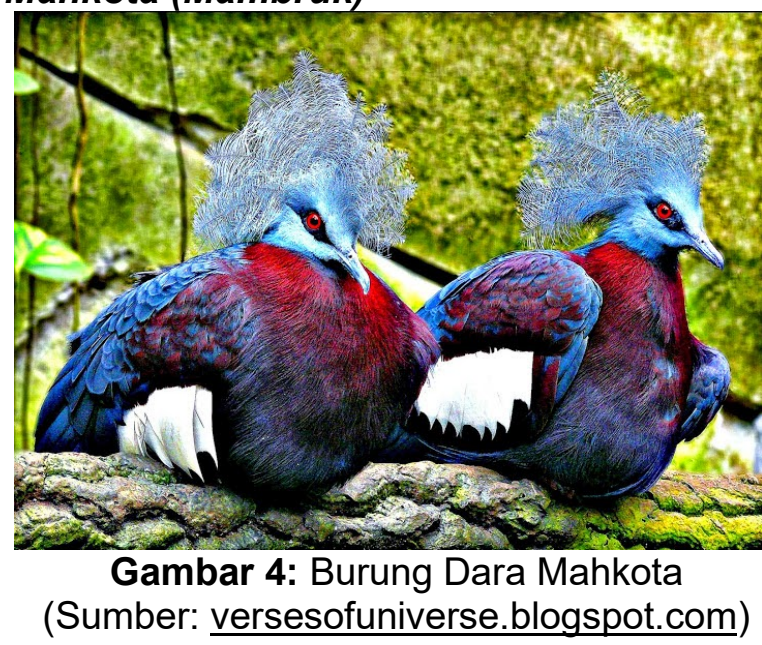


Mewakili karakter Dara yang memiliki sifat pemberani, cerdik, berjiwa kepemimpinan, serta memiliki kepercayaan diri yang tinggi.

\subsubsection{Burung Hantu}

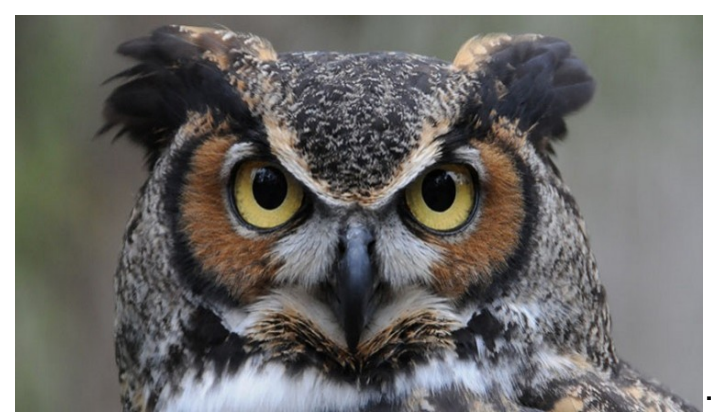

Gambar 5. Burung Hantu

(Sumber: sultantv.co)

Mewakili karakter Pak Burhan yang bijaksana. Sifatnya yang tenang namun disegani oleh orangorang disekitarnya, menambahkan ketegasan dalam pengambilan keputusan dalam permasalahan yg ada di cerita ini.

\subsection{Post-Production (Pasca Produksi)}

Fase Post Production adalah masa setelah berlangsungnya acara, di mana setiap divisi menyelesaikan laporan akhir mereka yang nantinya akan dijadikan satu dalam Final Report.

Dalam pembuatan seni pertunjukan akan ada banyak keperluan yang harus dipenuhi dari segi penataan artistik dan penataan non-artistik. Kedua aspek tersebut merupakan aspek-aspek yang harus diperhatikan dalam menggarap sebuah pertunjukan. Untuk penataan artistik yang dibutuhkan seperti, penulisan dan pemilihan naskah yang akan dipanggungkan, penyutradaraan, penataan busana, penataan rias wajah dan rambut, penataan suara dan musik, serta penataan artistik panggung. Sedangkan, untuk penataan non-artistik bertugas memfasilitasi dan membantu agar impian dari bagian artistik dapat terwujud seperti, mencari dan memilih tempat latihan, mengurus konsumsi, mengurus promosi, penjualan tiket, mengurus publikasi (membuat poster, brosur, atau leaflet), serta mencari sponsor. (Riantiarno, 2003, p.112-113) Untuk evaluasi pada konsep pertunjukan kolaborasi sirkus dengan kearifan lokal nusantara, pembuat karya akan melakukan pematangan konsep sehingga nantinya konsep ini dapat dipergunakan oleh pihak yang akan memakai konsep yang pembuat karya tawarkan.

Evaluasi sebuah acara adalah proses untuk mengetahui, menilai, dan mendapatkan informasi apakah kegiatan yang digelar telah terwujudkan dengan baik atau tidak. Evaluasi bermanfaat untuk dengan akurat dan efektif menentukan apakah tujuan pembuat konsep, yaitu, 'The Fabulous Fable Show: Circus and Theatre' mencapai hasil yang diinginkan.

\subsection{Evaluasi}

Evaluasi pertunjukan ini dapat dilakukan dengan cara:

\subsubsection{Box Polling Kepuasan Penonton}

Setelah menonton, para pengunjung akan diminta untuk mengisi polling kepuasan penonton kedalam box yang ditempatkan di sekitar pintu keluar tenda sirkus. Polling yang disediakan terdiri dari dua pilihan yaitu, puas dan tidak puas. 


\subsubsection{Media monitoring}

Pihak penyelenggara melakukan media monitoring untuk memantau media yang menyoroti acara ini sebagai bahan evaluasi pertunjukan yang telah dilaksanakan. Keterlibatan media yang telah menjadi rekanan resmi dalam pertunjukan ini diharapkan turut mempromosikan dan hadir untuk meliput sesuai dengan penawaran yang telah disepakati bersama. Tidak hanya rekanan resmi media, tetapi juga tidak menutup kemungkinan untuk pertunjukan ini mendapatkan sorotan dari media lain.

Adapun yang diawasi dalam media monitoring ini adalah umpan balik yang diberikan oleh mediamedia dari apa yang mereka tulis mengenai pertunjukan ini, apakah bersifat positif atau negatif.

Media monitoring untuk media cetak dilakukan dengan mengamati media yang terlibat di dalam acara, kemudian membaca artikel yang dikeluarkan oleh media tersebut mengenai pertunjukan yang diadakan.

Publikasi dari Media online dapat diawasi dengan menggunakan bantuan search engine Google menggunakan keywords nama pertunjukan yaitu, 'The Fabulous Fable Show; Circus and Theatre'. Alternatif lain untuk melakukan pengawasan media online adalah dengan melakukan pencarian pada media sosial menggunakan hashtag resmi dan kata kunci lain yang memungkinkan digunakan dalam publikasi pertunjukan ini, seperti:
1) \#TheFabulousFableShow
2) \#TFFShow
3) \#TFFSCircus

\subsubsection{Kuisioner Online}

Penonton yang memesan tiket secara online akan menerima email berupa link kuesioner singkat yang dapat diisi sampai hari ke-7 setelah acara berlangsung.

\subsubsection{Media Sosial}

Hal-hal yang berkaitan dengan 'The Fabulous Fable Show; Circus and Theatre' yang diunggah oleh para pengguna media sosial dapat serta menjadi evaluasi untuk penyelenggara. Dalam periode 1 minggu pasca pertunjukan, materi posting yang diunggah oleh penonton pertunjukan dipantau guna mempertimbangkan segala kekurangan dan kelebihan yang telah dicapai oleh pertunjukan ini.

Setelah ide-ide mengenai konsep rancangan pertunjukan kolaborasi sirkus dan kearifan lokal budaya nusantara yang berjudul 'The Fabulous Fable Show; Circus and Theatre' dituangkan dengan menjelaskan konsep, struktur organisasi, target sponsor, target pengunjung, perencanaan keuangan, materi promosi, campaign. Pertunjukan ini masih bisa ditingkatkan lagi.

Untuk menyelenggarakan pertunjukan ini, sebelumnya dapat diadakan sebuah intensive workshop untuk mempersiapkan dan meningkatkan sumber daya dan kemampuan pemain sirkus muda Indonesia yang bisa melakukan atraksi sirkus sekaligus menari dan bernyanyi.

Pada bagian evaluasi, dilihat apakah perencanaan acara yang dibuat, dapat diadaptasi untuk digunakan pada pertunjukan lainnya. Konsep pada pertunjukan ini juga dapat digunakan dengan judul cerita rakyat lainnya yang dikisahkan. Pertunjukan jenis ini juga dapat diadaptasi menjadi sebuah pertunjukan internasional dengan bahasa asing yang diadakan di dalam negeri maupun dalam bentuk tur keliling dunia, untuk memperkenalkan budaya-budaya Indonesia keluar negeri. 


\section{REFERENSI}

Ampera, Taufik. (2010). Pengajaran Sastra: Teknik Mengajar Sastra Anak Berbasis Aktivitas. Bandung: Widya Padjadjaran.

Astawa, N. (2019). Buku Cerita Fabel Berbasis Pendidikan Karakter Untuk Siswa Sekolah Dasar Kelas Tinggi. Jurnal Lentera Pendidikan Pusat, 4, 126-143. http://ojs.ummetro.ac.id/index.php/lentera/article/view/1144

CNN Indonesia. (2018, November 15). Kelompok Sirkus Legendaris Indonesia Bakal Tampil di GBK. Diakses pada 10/08/2020, dari https://www.cnnindonesia.com/gaya-hidup/20181115181538-269346912/kelompok-sirkus-legendaris-indonesia-bakal-tampil-di-gbk

Panolih, K. P. (2020, February 22). Kejayaan Legenda Sirkus Indonesia -. Kompas.Id. https://kompas.id/baca/riset/2020/02/23/kejayaan-legenda-sirkus-indonesia/

Rahwanda, A., Agustina, E., \& Sarwono, S. (2019). Pantun Pada Seni Pertunjukan Beroyal Dalam Bimbang Pernikahan Suku Melayu Di Desa Pasar Bembah. Jurnal Ilmiah Korpus, 3, 253-261. https:/ejournal.unib.ac.id/index.php/korpus/article/view/11627

Rizqi, V. L. P. (2018, November 25). Saksikan Hebatnya Sirkus Kelas Dunia, The Great 50 Show. $\begin{array}{lllll}\text { Diakses } & \text { pada } & 11 & \text { Agustus } & 2020, \\ \end{array}$ https://www.motherandbaby.co.id/article/2018/11/52/11289/Saksikan-Hebatnya-Sirkus-KelasDunia-The-Great-50-Show

Sedyawati, E. 2012. Budaya Indonesia Kajian Arkeologi, Seni, dan Sejarah. Jakarta: PT Raja Grafindo Persada.

Sumardjo, J., Dwimarwati, R., \& Jaeni. (2001). Seni Pertunjukan Indonesia: Suatu Pendekatan Sejarah. Bandung: STSI Press

Wall, D. (2013). The Ordinary Acrobat: A Journey into the Wondrous world of the Circus, Past and Present. Knopf Doubleday Publishing Group.

Zaidan, Abdul Rozak, Anita K. Rustapa, dan Haniah. (2007). Kamus Istilah Sastra. Jakarta: Balai Pustaka. 
Idealogy Journal

Volume 5 Issue 22020

溇 IDEALOGY

JOURNAL 